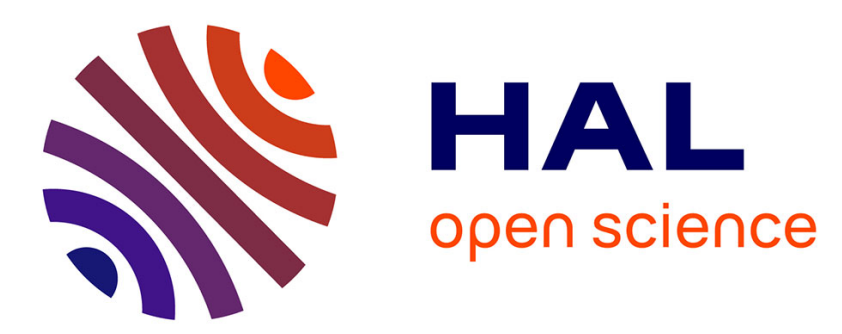

\title{
Machinability analysis of dry drilling of carbon/epoxy composites: cases of exit delamination and cylindricity error
}

\author{
M. F. Ameur, Malek Habak, M. Kenane, H. Aouici, Mohammed Cheikh
}

\section{- To cite this version:}

M. F. Ameur, Malek Habak, M. Kenane, H. Aouici, Mohammed Cheikh. Machinability analysis of dry drilling of carbon/epoxy composites: cases of exit delamination and cylindricity error. International Journal of Advanced Manufacturing Technology, 2017, 88 (9), pp.2557-2571. 10.1007/s00170-0168967-8 . hal-01620030

\section{HAL Id: hal-01620030 \\ https://hal.science/hal-01620030}

Submitted on 15 Mar 2019

HAL is a multi-disciplinary open access archive for the deposit and dissemination of scientific research documents, whether they are published or not. The documents may come from teaching and research institutions in France or abroad, or from public or private research centers.
L'archive ouverte pluridisciplinaire HAL, est destinée au dépôt et à la diffusion de documents scientifiques de niveau recherche, publiés ou non, émanant des établissements d'enseignement et de recherche français ou étrangers, des laboratoires publics ou privés. 


\title{
Machinability analysis of dry drilling of carbon/epoxy composites: cases of exit delamination and cylindricity error
}

\author{
M. F. Ameur ${ }^{1,2} \cdot$ M. Habak ${ }^{3}$ - M. Kenane $^{1} \cdot$ H. Aouici ${ }^{4} \cdot$ M. Cheikh ${ }^{5}$
}

\begin{abstract}
The aim of this work is to define the cutting conditions that allow the dry drilling of carbon fiber reinforced epoxy (CFRE) composite materials taking into consideration the quality of the drilled holes (the exit delamination factor and the cylindricity error) and the optimum combination of drilling parameters. A further aim is to use grey relational analysis to improve the quality of the drilled holes. The machining parameters were measured according to $3^{3}$ full factorial parameter designs (27 experiments with independent process variables). The experiments were carried out under various cutting parameters with different spindle speeds and feed rates. Drilling tests were done using WC carbide, high-speed steel (HSS), and TiN-coated carbide drills. The experiment design was accomplished by application of the statistical analysis of variance (ANOVA). Results show that the thrust force is mainly influenced by the tool materials and the feed rate, which has a strong influence on the exit delamination factor. On the other hand, the spindle speed particularly affects the
\end{abstract}

M. F. Ameur

faycalameur@gmail.com

Laboratoire des Sciences et Génie des Matériaux, Faculté de Génie Mécanique et Génie des Procédés USTHB, BP 32, El-Alia, Bab Ezzouar, Algeria

2 Ecole Nationale Supérieure de Technologie, Cité Diplomatique Dergana-Bordj El Kiffan, Alger, Algeria

3 Laboratoire des Technologies Innovantes (LTI), IUT d'Amiens, Dépt GMP, Université de Picardie Jules Verne, Avenue Facultés Bailly, 80001 Amiens, France

4 Laboratoire Mécanique et Structures (LMS), Département de Génie Mécanique, FST, Université 08 Mai 1945, Guelma 24000, Algeria

5 Université de Toulouse, IUT de Figeac, Mines Albi, ICA (Institut Clément Ader), Campus Jarlard, 81013 Albi cedex 09, France cylindricity error of the holes. Correlations were established between spindle speed/feed rate and the various machining parameters so as to optimize cutting conditions. These correlations were found by quadratic regression using response surface methodology (RSM). Finally, tests were carried out to check the concordance of experimental results.

Keywords CFRE composites $\cdot$ Response surface methodology $\cdot$ Dry drilling $\cdot$ Cutting parameters $\cdot$ Exit delamination factor $\cdot$ Cylindricity error

\section{Introduction}

In industrial fields such as aerospace and aircraft manufacturing, carbon fiber reinforced epoxy (CFRE) composites are used, because of their excellent mechanical properties. Drilling of composite materials is a very common process in the assembly of aeronautic composite structures. However, the machinability of these composites makes it difficult to yield good-quality products.

With regard to the quality characteristics of drilled holes in CFRE, some problems have been encountered, including surface delamination and fiber pullout. With the increasing demand for advanced composite materials, different cutting conditions are required. Delamination is the most common defect when drilling. This is because of the heterogeneity between fibers and matrix [1]. Some studies have concluded that the delamination factor is related to the thrust force when drilling composite materials [2].

Davim et al. [3] presented a correlation between cutting velocity and feed rate with the delamination of carbon fiber reinforced laminate composites. Recently, Tsao[[4] examined the drilling-induced thrust force of a composite polymer (CFRP) material, with a step-core drill, by taking into 
consideration the diameter ratio, feed rate, and spindle speed parameters. For the same material, Zitoune et al. [5] improved drilling by using various dimensions of a double cone drill with analysis including cutting force, tool lifetime, chip form, and hole quality. Elsewhere, Li et al. [6] detailed the effect of variable feed rate and lay-up configuration on surface roughness and integrity following the drilling of CFRP composites under chilled air conditions. Gaitonde et al. [7] analyzed the effects of process parameters on delamination under highspeed drilling using CFRP. Rawat et al. conducted similar experiments [8], but with carbon fiber and a different epoxy matrix. With the same carbon/epoxy composite plates, Piquet et al. [9] investigated the effect of drilling with two types of drills, a conventional twist drill and specific cutting tool. Luís Miguel et al. [10] performed drilling tests with different drills, and the resulting delamination extensions were measured by digital-enhanced radiography and evaluated using the computational techniques of image processing and analysis. Capello [11] studied the differences in delamination mechanisms in drilling with and without a support placed below the glass fiber reinforced plastic work piece. Bhatnagar et al. [12] studied the orthogonal cutting of unidirectional carbon fiber reinforced epoxy composite with different fiber orientations. Rajamurugan et al. [13] analyzed delamination in drilling glass fiber reinforced polyester composites. An attempt has been made to develop empirical relationships between the drilling parameters. Khashaba et al. [14] treated the effect of drill pre-wear on the machinability parameters when drilling glass fiber reinforced epoxy composites (GFRE) under different cutting conditions. Linear regression models were developed to correlate the machinability parameters with the drill wear and cutting conditions.

Rubio et al. [15] chose the Taguchi method to identify the best drilling setup of a glass reinforced polyamide. Another approach, based on a combination of Taguchi's techniques and the analysis of variance (ANOVA), was used to investigate the cutting characteristics of CFRP with high-speed steel (HSS) and cemented carbide drills [3]. In other studies, Sardinas et al. [16] used a micro-genetic algorithm and Krishnamoorthy et al. [17] a fuzzy grey method both with the aim of optimizing the drilling process conditions. Gaitonde et al. analyzed the effects of cutting speed, feed rate, and angle point on the delamination factor by generating response surface methodology (RSM) plots models [7].

Although numerous research studies have been carried out on the effects of cutting parameters on delamination during the drilling of CFRP composites, few have been reported on the effect of the geometric quality of the hole [18].

The studies mentioned above discuss the cutting of composite materials, but they make no assumptions about geometric cylindricity defects.

The present work investigates the dry drilling of carbon/ epoxy composite (CFRE) plates. The twisted tools used are from HSS, carbide, and TiN-coated carbide, all with the same dimensions $\left(6-\mathrm{mm}\right.$ diameter, $118^{\circ}$ point angle, and $30^{\circ}$ helical angle).

The effect of the cutting parameters (spindle speed and feed rate) on generated cutting forces and hole quality were studied. ANOVA was used to examine the significance and the relevance of the models used to draw the response surface in order to estimate the influence and the simultaneous interaction of the cutting parameters (rotation speed $(N)$ and feed rate $(f))$ on the studied phenomena (thrust force $(F z)$, torque $(M z)$, exit delamination factor, and the cylindricity error).

\section{Experimental procedure}

\subsection{Tests and materials}

Dry drilling experiments were carried out on a CNC vertical milling machine. Three different tool materials were used for the drill: HSS,-coated carbide, and carbide, with different spindle speeds and feed rates. Experimental results were collected and recorded by a data acquisition system. The experimental conditions are summarized in Table 1.

The material used in the present investigation consisted of CFRE plates (with dimensions of $200 \times 200 \times 8 \mathrm{~mm}^{3}$ ) manufactured through hand layup of $\left[90^{\circ} /+45^{\circ} / 0^{\circ} /-45^{\circ}\right]_{3 \mathrm{~s}}$ under a vacuum pressure of $97 \mathrm{MPa}$. The obtained thickness of the cured plate was of $8 \mathrm{~mm}$.

To check the homogeneity of the prepared composite plates and calculate the fiber volume fraction, three samples of $(10 \times 10 \times 8) \mathrm{mm}^{3}$ were cut off from different plates. The fiber content was determined by pyrolysis at a temperature of $450{ }^{\circ} \mathrm{C}$. The obtained volume fiber fraction was equal to $67.16 \%$ with a standard deviation estimated at $1.22 \%$. The mechanical properties of the material are described in Table 2.

The workpiece was mounted on a Kistler platform (9257B type) in order to measure the thrust force and the torque applied on the workpiece during the drilling process.

Geometric inside-hole defects were analyzed on a threedimensional measuring machine (CMM) with a spherical probe of $3 \mathrm{~mm}$ in diameter. The measurement of the inlet and the outlet hole diameters and the cylindricity error were obtained by palpation at 24 points on the circumference of the

Table 1 Cutting conditions

\begin{tabular}{ll}
\hline Process parameters & Levels of independent parameters \\
\hline Spindle speed, $N(\mathrm{rev} / \mathrm{min})$ & $3000,6000,9000$ \\
Feed rate, $f(\mathrm{~mm} / \mathrm{min})$ & $60,120,180$ \\
Tool materials & HSS, Carbide, TiN-coated carbide \\
\hline
\end{tabular}


Table 2 Properties of materials (fiber and resin)

\begin{tabular}{ll}
\hline Properties of the carbon fiber & Standard grade of carbon fiber \\
\hline Thickness of carbon fiber $\varnothing(\mu \mathrm{m})$ & 7 \\
Tensile strength $(\sigma)(\mathrm{GPa})$ & 4.3 \\
Young's modulus $(E)(\mathrm{GPa})$ & 238 \\
Density $(\rho)\left(\mathrm{g} / \mathrm{cm}^{3}\right)$ & 1.76 \\
Specific strength $(\mathrm{GPa})$ & 2.00 \\
Epoxy resin & Epoxy SR 1710 \\
Composite CFRE properties & \\
Longitudinal & Transverse \\
E $(\mathrm{MPa}) 127,150$ & 8625 \\
$\sigma_{\mathrm{u}}(\mathrm{MPa}) 1621$ & 36 \\
$\mathcal{E}_{\mathrm{u}}(\%) 1.3$ & 0.4 \\
\hline
\end{tabular}

hole at $2 \mathrm{~mm}$ from the upper (entry hole) and lower (exit hole) free surface, as shown in Fig. 1.

Fig. 1 Schematic of experimental processes
Delamination is a damage phenomenon, which occurs due to the anisotropy and brittleness of composite materials. The damage (delamination) surrounding the holes was measured using a tool maker's microscope. The exit delamination factor was calculated using the following equation:

$F d=\frac{D_{\max }}{d}$

where the parameters $F_{d}, D_{\max }$, and $d$ are the delamination factor, the maximum diameter measured in the damaged zone, and the diameter of the drill, respectively.

The exit delamination factor was calculated at the exit side of the drill. Performance characteristics, namely thrust force, torque, exit delamination, and cylindricity error, are presented in Table 3, along with

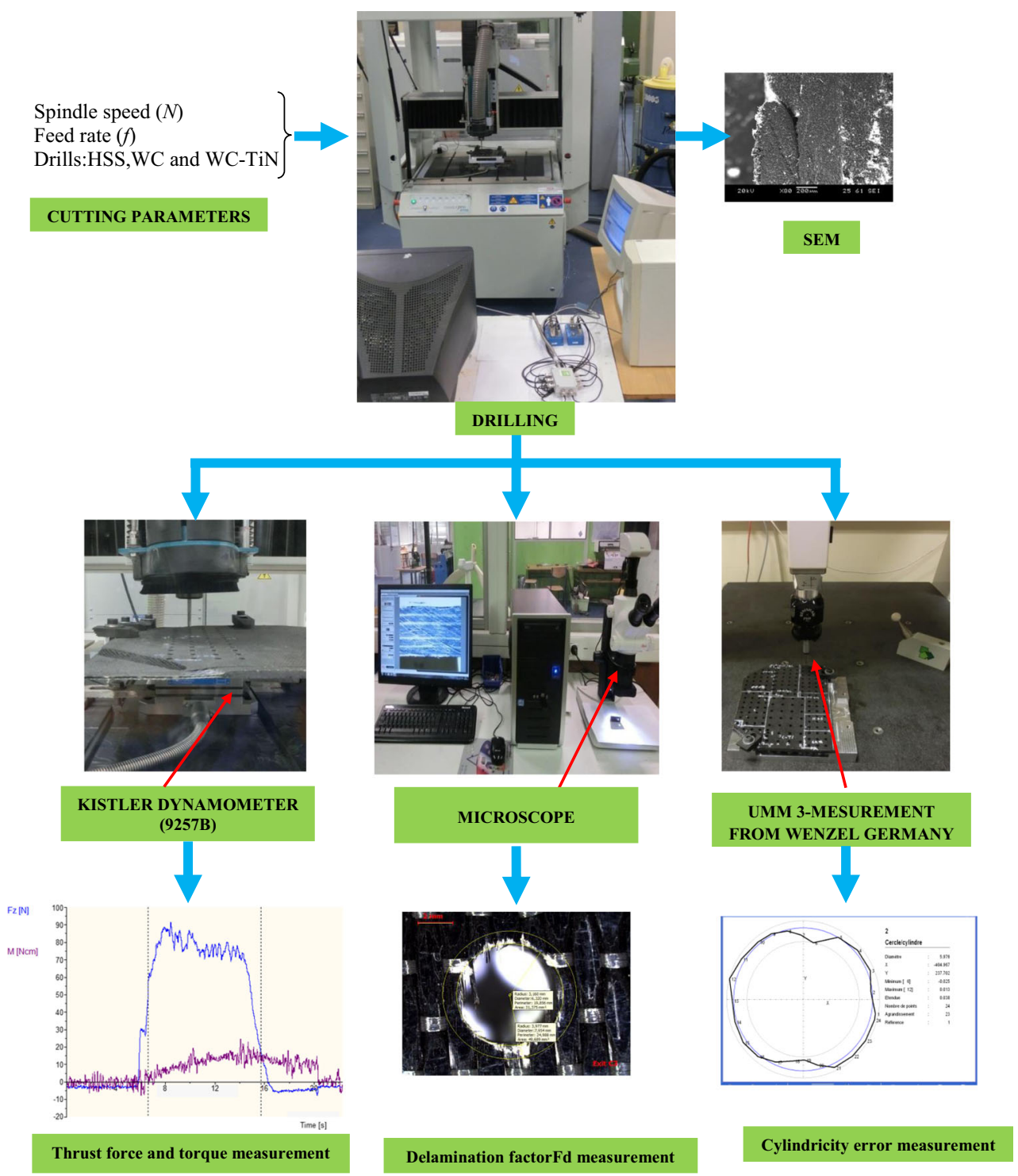


Table 3 Experimental results for $F z, M z, F_{d \text {-Exit }}$ and cylindricity error

\begin{tabular}{|c|c|c|c|c|c|c|c|}
\hline \multirow[t]{2}{*}{$\mathrm{N}^{\circ}$} & \multicolumn{3}{|c|}{ Machining parameters } & \multicolumn{4}{|c|}{ Response factors } \\
\hline & $N(\mathrm{rev} / \mathrm{min})$ & $f(\mathrm{~mm} / \mathrm{s})$ & Drill type & $F z(N)$ & $M z(N \times \mathrm{cm})$ & $F_{d-E x i t}$ factor & Cylindricity error (mm) \\
\hline 1 & 3000 & 60 & HSS & 72.39 & 11.28 & 1.223 & 0.052 \\
\hline 2 & 3000 & 60 & WC & 50.62 & 16.50 & 1.108 & 0.055 \\
\hline 3 & 3000 & 60 & WC-TiN & 59.29 & 8.91 & 1.140 & 0.036 \\
\hline 4 & 3000 & 120 & HSS & 96.69 & 12.90 & 1.355 & 0.042 \\
\hline 5 & 3000 & 120 & WC & 62.61 & 23.66 & 1.121 & 0.032 \\
\hline 6 & 3000 & 120 & WC-TiN & 73.15 & 10.17 & 1.142 & 0.025 \\
\hline 7 & 3000 & 180 & HSS & 121.60 & 14.71 & 1.368 & 0.046 \\
\hline 8 & 3000 & 180 & WC & 65.31 & 25.16 & 1.146 & 0.037 \\
\hline 9 & 3000 & 180 & WC-TiN & 81.11 & 13.34 & 1.215 & 0.026 \\
\hline 10 & 6000 & 60 & HSS & 50.79 & 16.33 & 1.276 & 0.054 \\
\hline 11 & 6000 & 60 & WC & 34.42 & 16.51 & 1.118 & 0.070 \\
\hline 12 & 6000 & 60 & WC-TiN & 39.19 & 12.52 & 1.081 & 0.064 \\
\hline 13 & 6000 & 120 & HSS & 77.02 & 18.17 & 1.281 & 0.049 \\
\hline 14 & 6000 & 120 & WC & 47.27 & 25.34 & 1.144 & 0.064 \\
\hline 15 & 6000 & 120 & WC-TiN & 55.09 & 14.32 & 1.132 & 0.045 \\
\hline 16 & 6000 & 180 & HSS & 96.68 & 20.71 & 1.347 & 0.050 \\
\hline 17 & 6000 & 180 & WC & 53.49 & 27.45 & 1.199 & 0.060 \\
\hline 18 & 6000 & 180 & WC-TiN & 67.03 & 14.67 & 1.183 & 0.039 \\
\hline 19 & 9000 & 60 & HSS & 40.83 & 11.42 & 1.219 & 0.091 \\
\hline 20 & 9000 & 60 & WC & 28.34 & 12.03 & 1.108 & 0.084 \\
\hline 21 & 9000 & 60 & WC-TiN & 30.79 & 10.44 & 1.183 & 0.070 \\
\hline 22 & 9000 & 120 & HSS & 30.33 & 11.64 & 1.282 & 0.079 \\
\hline 23 & 9000 & 120 & WC & 38.78 & 13.02 & 1.134 & 0.064 \\
\hline 24 & 9000 & 120 & WC-TiN & 44.74 & 10.80 & 1.136 & 0.050 \\
\hline 25 & 9000 & 180 & HSS & 69.15 & 10.82 & 1.340 & 0.071 \\
\hline 26 & 9000 & 180 & WC & 43.03 & 13.77 & 1.159 & 0.068 \\
\hline 27 & 9000 & 180 & WC-TiN & 55.50 & 8.23 & 1.161 & 0.052 \\
\hline
\end{tabular}

the input drilling parameters (spindle speed, feed rate, and tool materials).

\subsection{Response surface methodology}

Response surface methodology is a collection of mathematical and statistical techniques that are useful for the modeling and analysis of problems in which a response of interest is influenced by several variables and the purpose is to optimize this response $[14,18]$. In our study, the response surface methodology (RSM) comprised the following six major components:

(1) Defining the independent input variables and the desired output responses.

(2) Drawing up an experimental design plan.

(3) Using response surface regression equations to find the relationship between the factors $F z, M z, F_{d-E x i t}$, and cylindricity error by quadratic regression.
(4) Using ANOVA statistical analysis to find parameters which significantly affect the output.

(5) Obtaining the optimal set of experimental parameters that produces a maximum or minimum output value.

(6) Verifying and confirming the predicted performance characteristics by experiment.

\section{Results and discussion}

The machining parameters were measured according to $3^{3}$ full factorial designs (27 experiments with actual independent process variables). The measured responses (output) are shown in Table 2. They were analyzed by Design-Expert software which indicated that quadratic models were statistically recommended. 


\subsection{Regression equations}

RSM leads to an appropriate approximation for the true functional relationship between design parameters $Y$ and a set of independent variables. Usually, a secondorder model is used in response surface methodology $[19,20]$ :

$$
Y=b_{0}+\sum_{i=1}^{k} b_{i} x_{i}+\sum_{i=1}^{k} b_{i i} x_{i}^{2}+\sum_{i<j}^{k} b_{i j} x_{i} x_{j}+\varepsilon
$$

where $x_{i}$ is the value of the $i$ th machining process parameter. The terms $b_{0}, b_{1} \ldots b_{\mathrm{k}}$, and $b_{11}, . ., b_{k k}$ represent the regression coefficients. The residual $\varepsilon$ indicates the experimental error. The second-order response surface $Y$ is a function of the cutting parameters (the spindle speed $N$ and feed rate $f$ ). The relationship between the response and the machining parameters is given by:

$$
Y=b_{0}+b_{1} N+b_{2} f+b_{3} N^{2}+b_{4} f^{2}+b_{5} N \times f
$$

where $b_{0}, \ldots, b_{5}$ are the regression coefficients associated with the model.

The relationship between the design and the cutting parameters were modeled by quadratic regression. For the thrust force $F_{z}$, the models are given in Eqs. 4-6 for three different tool materials, namely carbide, highspeed steel, and TiN-coated carbide drills. Their coefficients of determination $\left(R^{2}\right)$ are $95.26,99.40$, and $99.64 \%$, respectively.

$$
\begin{aligned}
& F z_{(H S S)}= 75.01889-0.035139 \times f-8.74444 \times 10^{-4} \\
& \times N-2.90139 \times 10^{-5} \times f \times N+2.00741 \\
& \times 10^{-3} \times f^{2}-3.33148 \times 10^{-7} \times N^{2} \\
& F z_{(W C)}= 51.64333+0.38025 \times f-7.87278 \times 10^{-3} \\
& \times N-2.46716 \times 10^{-20} \times f \times N-1.02361 \times 10^{-18} \\
& \times f^{2}+3.39444 \times 10^{-7} \times N^{2} \\
& F z_{(W C \cdot T i N)}=66.76667+0.3275 \times f-9.94611 \times 10^{-3} \\
& \times N+4.01389 \times 10^{-6} \times f \times N-6.04167 \times 10^{-4} \\
& \quad \times f^{2}+4.06667 \times 10^{-7} \times N^{2}
\end{aligned}
$$

The torque $(M z)$ models are given in Eqs. 7 to 9. Their coefficients of determination $R^{2}$ are $96.77,94.91$, and $94.42 \%$.

$$
\begin{aligned}
& M z_{(H S S)}=-11.54333+0.055278 \times f+8.76 \times 10^{-3} \\
& \quad \times N-5.59722 \times 10^{-6} \times f \times N-6.94444 \times 10^{-6} \\
& \quad \times f^{2}-6.97222 \times 10^{-7} \times N^{2} \\
& M z_{(W C)}=-12.08444+0.25717 \times f+7.33889 \times 10^{-3} \\
& \quad \times N-9.61111 \times 10^{-6} \times f \times N-5.84259 \times 10^{-4} \\
& \quad \times f^{2}-6.38148 \times 10^{-7} \times N^{2}
\end{aligned}
$$

$$
\begin{aligned}
& M z_{(\text {WC } T \text { TiN })}=-8.73556+0.094917 \times f+5.63833 \\
& \times 10^{-3} \times N-9.22222 \times 10^{-6} \times f \times N-1.14352 \\
& \times 10^{-4} \times f^{2}-3.91296 \times 10^{-7} \times N^{2}
\end{aligned}
$$

The delamination-exit $\left(F_{d-E x i t}\right)$ factor models are shown in Eqs. 10 to 12 with coefficients of determination $R^{2}$ of 83.95 , 92.32, and $79.28 \%$, respectively.

$$
\begin{aligned}
& F_{d-\operatorname{Exit}(H S S)}=1.151+1.83611 \times 10^{-3} \times f+2.833 \\
& \times 10^{-6} \times N-3.3333 \times 10^{-8} \times f \times N-2.91667 \\
& \times 10^{-6} \times f^{2}-3.88889 \times 10^{-10} \times N^{2} \\
& F_{d-\operatorname{Exit}(W C)}=1.02622-8.05556 \times 10^{-5} \times f+3.17222 \\
& \times 10^{-5} \times N+1.80556 \times 10^{-8} \times f \times N+1.85185 \\
& \times 10^{-6} \times f^{2}-2.7037 \times 10^{-9} \times N^{2} \\
& F_{d-\operatorname{Exit}(W C-T i N)}=1.1918-3.5 \times 10^{-4} \times f-2.58889 \times 10^{-5} \\
& \times N-1.34722 \times 10^{-7} \times f \times N+6.62037 \times 10^{-6} \\
& \times f^{2}+3.42593 \times 10^{-9} \times N^{2}
\end{aligned}
$$

The cylindricity error models are illustrated in Eqs. 13 to 15 with coefficients of determination $R^{2}$ of $98.41,96.12$, and $97.4 \%$, respectively.

$$
\begin{aligned}
& \text { Cylindricty } \times \operatorname{error}_{(H S S)}=0.07667-2.3333 \times 10^{-4} \\
& \times f-8.7222 \times 10^{-6} \times N-1.9444 \times 10^{-8} \times f \times N \\
& +1.1111 \times 10^{-6} \times f^{2}+1.3889 \times 10^{-10} \times N^{2}
\end{aligned}
$$




$$
\begin{aligned}
& \text { Cylindricy } \times \operatorname{error}_{(W C)}=0.04867-7.3889 \times 10^{-4} \times f \\
& +1.5444 \times 10^{-5} N+2.7778 \times 10^{-9} \times f \times N+2.5 \\
& \times 10^{-6} \times f^{2}-8.88889 \times 10^{-10} \times N^{2}
\end{aligned}
$$

$$
\begin{aligned}
& \text { Cylindricty } \times \operatorname{error}_{(W C \cdot T i N)}=0.03211-6.0278 \times 10^{-4} \times f \\
& +1.4278 \times 10^{-5} N-1.1111 \times 10^{-8} \times f \times N \\
& +2.17593 \times 10^{-6} \times f^{2}-6.85185 \times 10^{-10} \times N^{2}
\end{aligned}
$$

\subsection{Statistical analysis}

The analysis of variance (ANOVA) method consists of fractioning the total variation in an experiment into components ascribable to controlled factors and errors.

Table 4 summarizes the variant analysis results of the thrust force $(F z)$, torque $(M z)$, delamination exit factor $\left(F_{d-E x i t}\right)$, and cylindricity error, respectively, of composite (CFRE) drilling. This analysis was carried out for a significance level of $5 \%$, i.e., for a confidence level of $95 \%$. These tables indicate the degree of freedom DF, sum of squares SC sq., mean square MS, $F$ values, probabilities ( $P$ value), and the percentage of contribution (Cont. \%) of each factor to the total variation. At the bottom of each table, the values of the determination coefficients $R^{2}$, the adjusted $R^{2}\left(\left(\operatorname{Adj}-R^{2}\right)\right.$, the predicted $R^{2}((\operatorname{Pred}-$ $R^{2}$ ), and the adequate precision are given.

The analysis of the first part of Table 4 shows that the feed rate, tool, the interactions $N \times$ tool, tool $\times$ tool, and especially the spindle speed (with a contribution of $41.68 \%$ ) have a great influence on the thrust force. The interactions $(N \times f),(f \times$ tool), $(N \times N)$, and $(f \times f)$ do not present any significant contribution on the obtained thrust force. Their contributions are $0.22,1.66,0.08$, and $0.01 \%$, respectively.

Furthermore, $R^{2}$ is $91.27 \%$, Adj- $R^{2}$ is $86.64 \%$, and Pred$R^{2}$ is $78.11 \%$. Therefore, in this case, the value of the Pred- $R^{2}$ is in reasonable agreement with the Adj- $R^{2}$ value. Thus, the thrust force model can be used to navigate the response space. Adequate precision compares the range of predicted values at the design points to the average prediction error. It is a measure of the signal to noise ratio. A ratio greater than 4 indicates adequate model precision, and in this particular case, it was found to be 19.18, which is well above the adequate precision limit.

In the second part of Table 4, the torque $(M z)$ is presented. These results show that the interaction tool $\times$ tool (Cont. $=41.25 \%)$ and interaction spindle speed $N \times N$ $($ Cont. $=26.88 \%)$ have the most significant influence on the torque $(M z)$. However, the spindle speed (Cont. $=11.02)$, the feed rate $($ Cont. $=10.05 \%)$, and the tool $($ Cont. $=5.61 \%)$ are less significant. These results also show that $N \times f, N \times$ tool, $f \times$ $f$, and $f \times$ tool interactions are negligible. The model works well in torque analysis with $R^{2}$ equal to $83.48 \%$ which indicates a more preponderant fit of the model. The Pred- $R^{2}$ of $59.66 \%$ is in reasonable agreement with the $\operatorname{Adj}-R^{2}$ of $74.73 \%$. The signal to noise ratio obtained here is 10.37 , which is well above 4 and shows an adequate signal.

It is clear from the ANOVA results that the tool is the dominant factor affecting the exit delamination factor $\left(F_{d-}\right.$ Exit) (third part of Table 4) with a contribution of $57.06 \%$. The second factor influencing $F_{d-E x i t}$ is the tool $\times$ tool interaction (Cont. $=27.65)$. The interaction feed rate has a contribution of $14.12 \%$. It is the most significant parameter related to the exit delamination factor. The spindle speed $N$ and interactions $N \times f, N \times$ tool, $N \times N, f \times f$, tool $\times$ tool, and the tool factor do not present any significant contribution to the obtained $F_{d-}$ Exit. The model for surface roughness gives values of $R^{2}$, Adj$R^{2}$, and Pred- $R^{2}$ of $92.33,88.26$, and $78.16 \%$, respectively. It is worth mentioning that the Pred- $R^{2}$ is in reasonable agreement with the Adj- $R^{2}$. These values should be used as indications of correctness of fit.

Finally, the results in the fourth part of Table 4 (cylindricity error) indicate that the model is still significant. Spindle speed $($ Cont. $=63.38 \%)$, feed rate $($ Cont. $=13.23 \%)$, cutting tool $($ Cont. $=13.23 \%)$, second-order effect of tool (tool $\times$ tool) $($ Cont. $=4.41 \%)$, and feed rate $(f \times f)($ Cont. $=4.27 \%)$ are the significant terms of the model. The spindle speed is the most significant factor related to cylindricity error. This is expected because it is well known that with the increase in the spindle speed, tool vibration increases. This induces an increase in the cylindricity error [11]. The ANOVA table indicates that the interactions $(N \times f),(N \times$ tool $),(f \times$ tool $)$, and $(N \times N)$ do not present any significant contribution to the cutting temperature obtained (calculated value of $F$ is more than the table value; $\left.F_{0.05,1,17}=4.45\right)$ at $95 \%$ confidence level. The value of $R^{2}$ is $90.10 \%$ of the total variability, $\operatorname{Adj}-R^{2}$ is $84.87 \%$, and the Pred- $R^{2}$ is $76.26 \%$. The latter is in reasonable agreement with the value of $\operatorname{Adj}-R^{2}$. Adequate precision of 14.83 is an adequate value for the model to perform well in prediction.

\subsection{Pareto graph}

To give better view of the results of the analysis of variance, Pareto graphs were built (see Fig. 2). This figure ranks the cutting parameters and their interactions according to their growing influence on the thrust force $(F z)$, torque $(M z)$, exit delamination factor $\left(F_{d \text {-Exit }}\right)$, and cylindricity error. Standardized values for this figure were obtained by dividing the effect of each factor by the error on the estimated value of the corresponding factor. If the $F$ values were greater than 4.45 , the effects were considered to be significant. Conversely, if the $F$ value was less than 4.45 , the effects were 
Table 4 ANOVA result-model variation

\begin{tabular}{|c|c|c|c|c|c|c|c|c|c|c|}
\hline Source & Sum of squares & $\mathrm{DF}$ & Mean square & $F$ value & Prob. & Cont. \% & $R^{2} \%$ & Adj- $R^{2} \%$ & Pred- $R^{2} \%$ & $\mathrm{AP}$ \\
\hline \multicolumn{11}{|c|}{ Thrust force $(F z)$} \\
\hline Model & 12097.63 & 9 & 1344.18 & 19.74 & $<0.0001$ & & 91.27 & 86.64 & 78.11 & 19.18 \\
\hline$N$ & 5042.76 & 1 & 5042.76 & 74.05 & $<0.0001$ & 41.68 & & & & \\
\hline$F$ & 3368.56 & 1 & 3368.56 & 49.47 & $<0.0001$ & 27.84 & & & & \\
\hline Tool & 1243.18 & 1 & 1243.18 & 18.26 & 0.0005 & 10.28 & & & & \\
\hline$N \times f$ & 27.00 & 1 & 27.00 & 0.40 & 0.5373 & 0.22 & & & & \\
\hline$N \times$ tool & 383.64 & 1 & 383.64 & 5.63 & 0.0297 & 3.17 & & & & \\
\hline$f \times$ tool & 200.49 & 1 & 200.49 & 2.94 & 0.1044 & 1.66 & & & & \\
\hline$N \times N$ & 9.21 & 1 & 9.21 & 0.14 & 0.7176 & 0.08 & & & & \\
\hline$f \times f$ & 1.25 & 1 & 1.25 & 0.018 & 0.8940 & 0.01 & & & & \\
\hline Tool $\times$ tool & 1821.55 & 1 & 1821.55 & 26.75 & $<0.0001$ & 15.06 & & & & \\
\hline Error & 1157.67 & 17 & 68.10 & & & & & & & \\
\hline Total & 13255.30 & 26 & & & & 100 & & & & \\
\hline \multicolumn{11}{|l|}{ Torque $(M z)$} \\
\hline Model & 598.89 & 9 & 66.54 & 9.54 & $<0.0001$ & & 83.48 & 74.73 & 59.66 & 10.37 \\
\hline$N$ & 65.97 & 1 & 65.97 & 9.46 & 0.0068 & 11.02 & & & & \\
\hline$F$ & 60.21 & 1 & 60.21 & 8.64 & 0.0092 & 10.05 & & & & \\
\hline Tool & 33.57 & 1 & 33.57 & 4.81 & 0.0424 & 5.61 & & & & \\
\hline$N \times f$ & 25.78 & 1 & 25.78 & 3.70 & 0.0714 & 4.30 & & & & \\
\hline$N \times$ tool & 0.35 & 1 & 0.35 & 0.051 & 0.8245 & 0.06 & & & & \\
\hline$f \times$ tool & 0.67 & 1 & 0.67 & 0.096 & 0.7600 & 0.11 & & & & \\
\hline$N \times N$ & 160.99 & 1 & 160.99 & 23.09 & 0.0002 & 26.88 & & & & \\
\hline$f \times f$ & 4.30 & 1 & 4.30 & 0.62 & 0.4430 & 0.72 & & & & \\
\hline Tool $\times$ tool & 247.04 & 1 & 247.04 & 35.43 & $<0.0001$ & 41.25 & & & & \\
\hline Error & 118.52 & 17 & 6.97 & & & & & & & \\
\hline Total & 717.42 & 26 & & & & 100 & & & & \\
\hline \multicolumn{11}{|l|}{$F_{\text {d exit }}$} \\
\hline Model & 0.17 & 9 & 0.019 & 22.73 & $<0.0001$ & & 92.33 & 88.26 & 78.16 & 15.58 \\
\hline$N$ & $5.120 \mathrm{E}-004$ & 1 & $5.120 \mathrm{E}-004$ & 0.61 & 0.4470 & 0,30 & & & & \\
\hline$F$ & 0.024 & 1 & 0.024 & 28.81 & $<0.0001$ & 14,12 & & & & \\
\hline Tool & 0.097 & 1 & 0.097 & 114.21 & $<0.0001$ & 57,06 & & & & \\
\hline$N \times f$ & $9.720 \mathrm{E}-004$ & 1 & $9.720 \mathrm{E}-004$ & 1.15 & 0.2985 & 0,57 & & & & \\
\hline$N \times$ tool & $6.453 \mathrm{E}-004$ & 1 & $6.453 \mathrm{E}-004$ & 0.76 & 0.3944 & 0,38 & & & & \\
\hline$f \times$ tool & $2.760 \mathrm{E}-003$ & 1 & $2.760 \mathrm{E}-003$ & 3.27 & 0.0884 & 1,62 & & & & \\
\hline$N \times N$ & $6.000 \mathrm{E}-006$ & 1 & $6.000 \mathrm{E}-006$ & $7.100 \mathrm{E} 003$ & 0.9338 & 0,00 & & & & \\
\hline$f \times f$ & $2.667 \mathrm{E}-004$ & 1 & $2.667 \mathrm{E}-004$ & 0.32 & 0.5816 & 0,16 & & & & \\
\hline Tool $\times$ tool & 0.047 & 1 & 0.047 & 55.40 & $<0.0001$ & 27,65 & & & & \\
\hline Error & 0.014 & 17 & $8.450 \mathrm{E}-004$ & & & & & & & \\
\hline Total & 0.19 & 26 & & & & 100 & & & & \\
\hline \multicolumn{11}{|c|}{ Cylindricity error } \\
\hline Model & $6.774 \mathrm{E}-003$ & 9 & $7.527 \mathrm{E}-004$ & 17.20 & $<0.0001$ & & 90.10 & 84.87 & 76.26 & 14.83 \\
\hline$N$ & 4.294E-003 & 1 & 4.294E-003 & 98.11 & $<0.0001$ & 63.38 & & & & \\
\hline$F$ & $8.961 \mathrm{E}-004$ & 1 & 8.961E-004 & 20.47 & 0.0003 & 13.23 & & & & \\
\hline Tool & $8.961 \mathrm{E}-004$ & 1 & 8.961E-004 & 20.47 & 0.0003 & 13.23 & & & & \\
\hline$N \times f$ & 3.333E-005 & 1 & $3.333 \mathrm{E}-005$ & 0.76 & 0.3950 & 0.49 & & & & \\
\hline$N \times$ tool & $2.133 \mathrm{E}-005$ & 1 & $2.133 \mathrm{E}-005$ & 0.49 & 0.4945 & 0.31 & & & & \\
\hline$f \times$ tool & $4.408 \mathrm{E}-005$ & 1 & $4.408 \mathrm{E}-005$ & 1.01 & 0.3296 & 0.65 & & & & \\
\hline$N \times N$ & $1.852 \mathrm{E}-006$ & 1 & 1.852E-006 & 0.042 & 0.8395 & 0.03 & & & & \\
\hline$f \times f$ & 2.894E-004 & 1 & 2.894E-004 & 6.61 & 0.0198 & 4.27 & & & & \\
\hline Tool $\times$ tool & $2.987 \mathrm{E}-004$ & 1 & $2.987 \mathrm{E}-004$ & 6.82 & 0.0182 & 4.41 & & & & \\
\hline Error & $7.440 \mathrm{E}-004$ & 17 & $4.376 \mathrm{E}-005$ & & & & & & & \\
\hline Total & $7.518 \mathrm{E}-003$ & 26 & & & & 100 & & & & \\
\hline
\end{tabular}

not considered significant. The confidence interval chosen was $95 \%$. $F$ table corresponding to a $95 \%$ confidence level in the accurate calculation of the process parameters was $F_{0.05}$, $1,17=4.45$.

To verify the adequacy of the model obtained by ANOVA analysis, the normality assumption of the residual must be verified. Figure 3a, b shows normal probability plots of the residuals. These figures reveal that all the residuals follow a straight line pattern which is in good agreement with the results reported by Shahrajabian et al. [21].

\section{Response surface analysis}

A 3D response surface model was generated to exhibits the interaction effects due to spindle speed $N$ and feed 

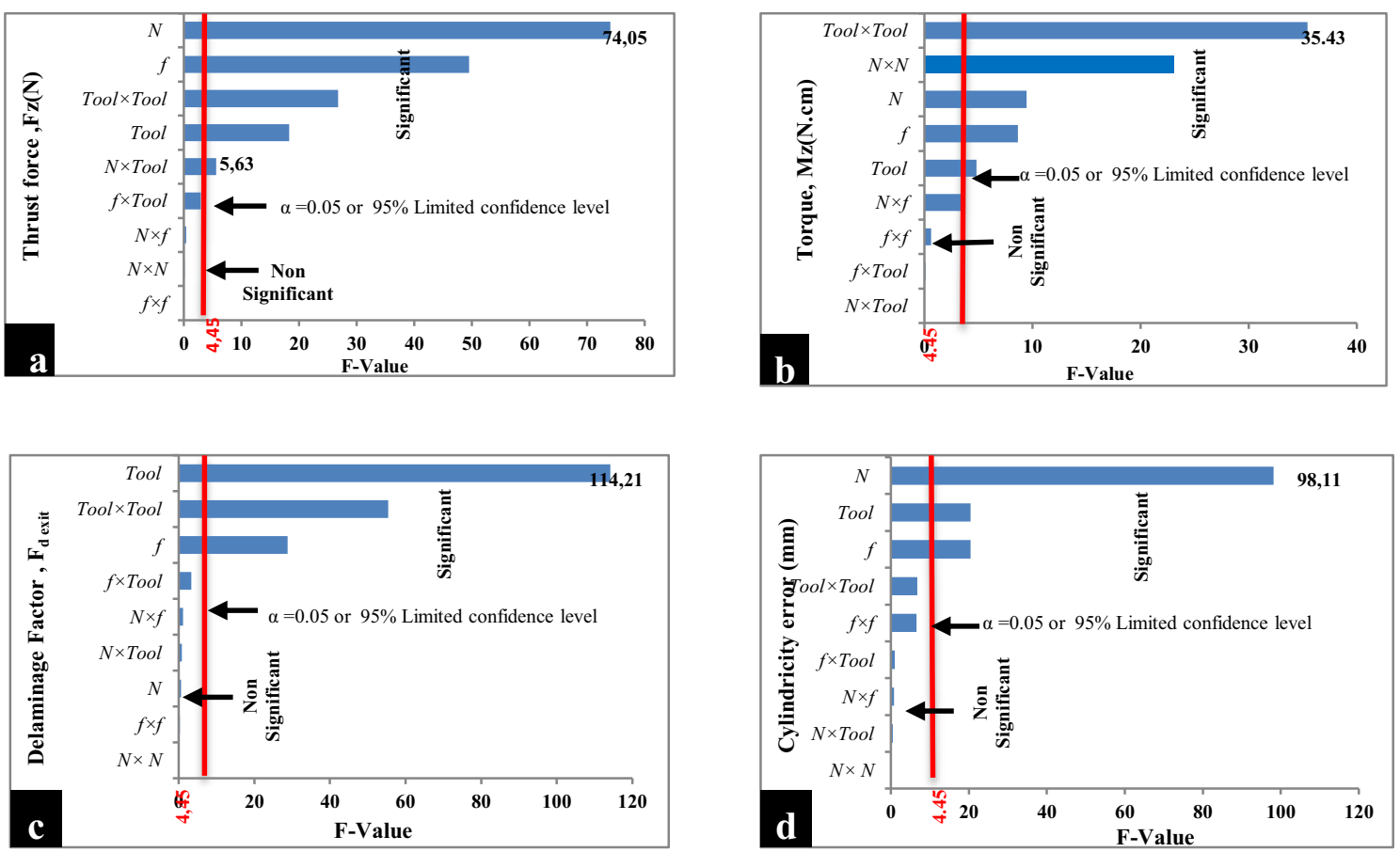

Fig. 2 Pareto graph:,a Thrust force, $\mathbf{b}$ torque, $\mathbf{c}$ exit delamination factor, and $\mathbf{d}$ cylindricity error

(a) Thrust force

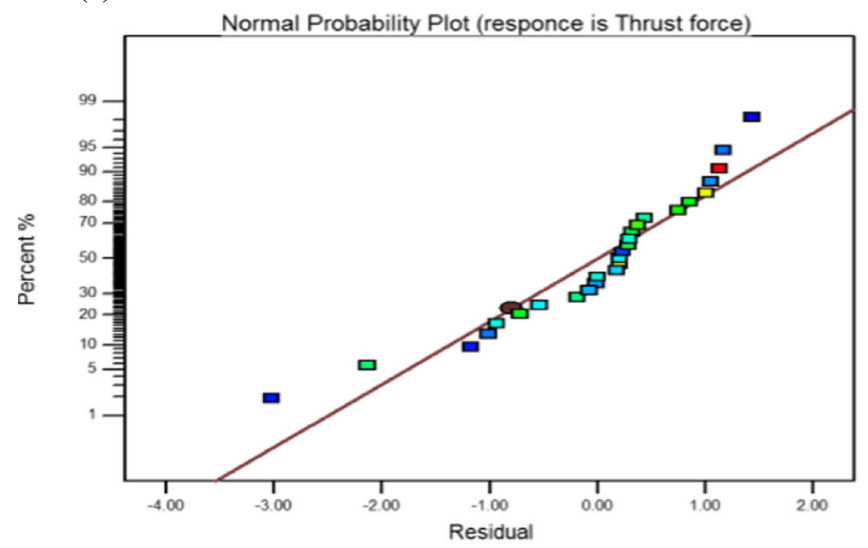

(c)Exitdelamination factor

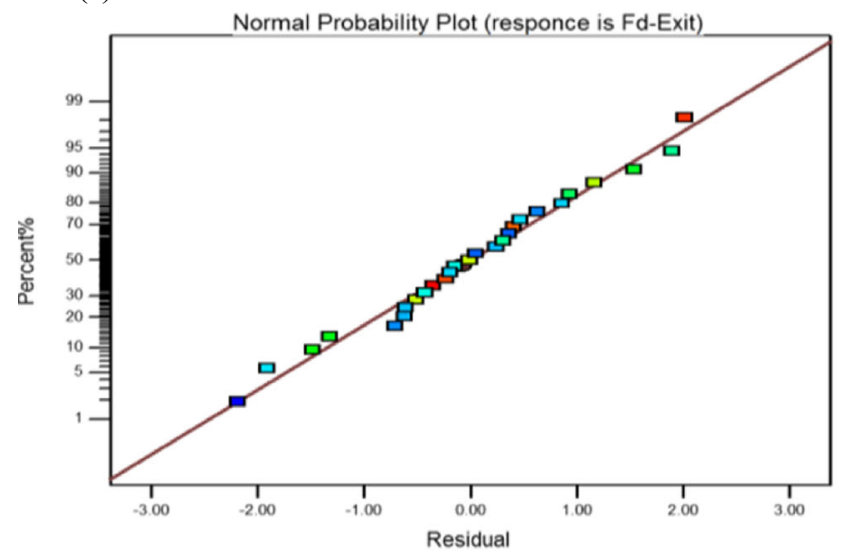

Fig. 3 Normal probability plot of residuals for each response (b) Torque

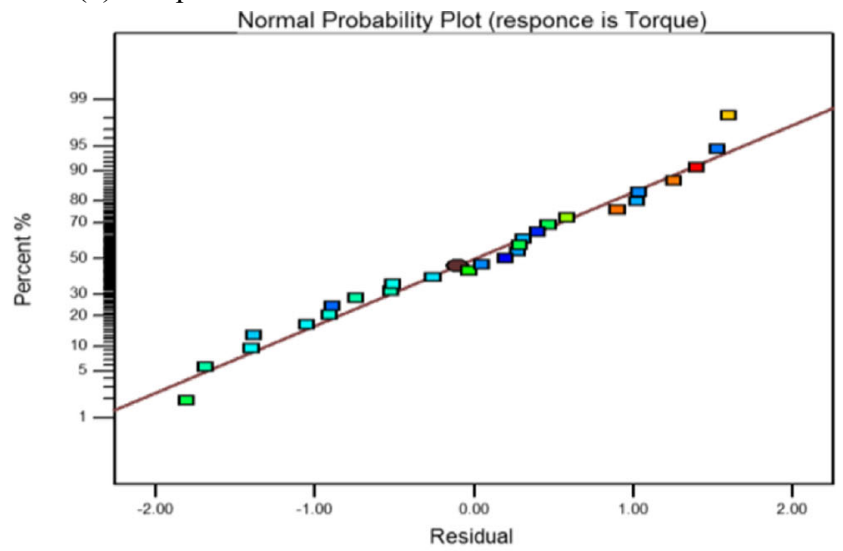

(d) Cylindricity error

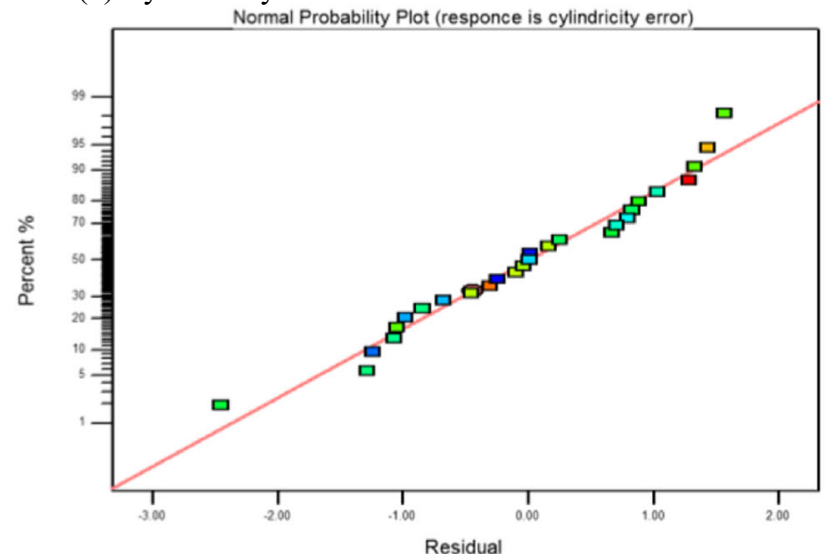


rate $f$ on thrust force $F z$, torque $M z$, delamination factor at the exit $\left(F_{d-E x i t}\right)$, and the cylindricity error during drilling of CFRE composites. These were analyzed for three different drill materials: high-speed steel, carbide, and coated carbide through response surface plots (Figs. 4, 5, 6, and 7).

\subsection{Effect of drilling parameters on thrust forces}

The thrust force generated during drilling of CFRE composites depends on input variables, such as cutting speed or spindle speed, feed rate, and drill materials. This effect is summarized in Fig. 4. The thrust force greatly increases with the feed rate. However, the thrust force changes only slightly when the spindle speed varies. It can also be observed in this figure that drilling with the HSS drill leads to a higher thrust force compared to WC and WC-TiN drills. Furthermore, it can be noticed that for a spindle speed of $3000 \mathrm{rev} / \mathrm{min}$ with a feed rate varying from 60 to $180 \mathrm{~mm} / \mathrm{min}$, the drilling thrust force of CFRE composites using WC,WC-TiN, and HSS tools is subjected to an increase of 22.64, 26.64 , and $40.47 \%$, respectively.

From these figures, it was noted that for the smallest feed rate $(60 \mathrm{~mm} / \mathrm{min})$ and a spindle speed varying from 3000 (rev/min) to $9000(\mathrm{rev} / \mathrm{min})$, the thrust force for the three drills (HSS, WC, and WC-TiN) was slightly reduced. It is known that increasing the spindle speed raises the temperature of machining, which is due to the friction between the tool and the CFRE composite materials, which in turn results in a softening of the material and a subsequent reduction in thrust force [20].

\subsection{Effect of drilling parameters on torque}

Drilling torque obtained from the regression model and the optimum torque for the three drills (HSS, WC, and WCTiN) is exhibited by the three-dimensional response surface model shown in Fig. 5. It can be observed that the torque increases noticeably with the feed rate for the three drilling tools. Drill materials have a significant effect on the torque during the drilling of the CFRE composites. In addition, maximal torque values are obtained when drilling composite laminates with a speed spindle of $6000 \mathrm{rev} / \mathrm{min}$, for all three tool materials. For the same spindle speed of $6000 \mathrm{rev} / \mathrm{min}$, the WC drill was subjected to the highest torque value when the feed rate was $180 \mathrm{~mm} / \mathrm{min}$.

Furthermore, Fig. 5 indicates that at a high spindle speed (9000 rev/min) and a low feed rate $(60 \mathrm{~mm} / \mathrm{min})$, the three drills were subjected to a low torque value in the drilling of CFRE composites.

\subsection{Effect of drilling parameters on the exit delamination factor}

From the response surface analysis in Fig. 6, it can be seen that the exit delamination factor is highly sensitive to the feed rate variation. It can also be observed from Fig. 6 that delamination has a tendency to increase with the feed rate during drilling of CFRE composites for the different drills (HSS, WC, and WC-TiN). In addition, the HSS drill has the greatest effect on delamination compared with the other tools.

Figure 6 clearly shows that the combination of low values of feed rate and spindle speed is useful in the WC tool during drilling of CFRE composites in order to reduce damage at the
Fig. 4 Effect of spindle speed and feed rate on thrust force for HSS, carbide, and TiN-coated carbide

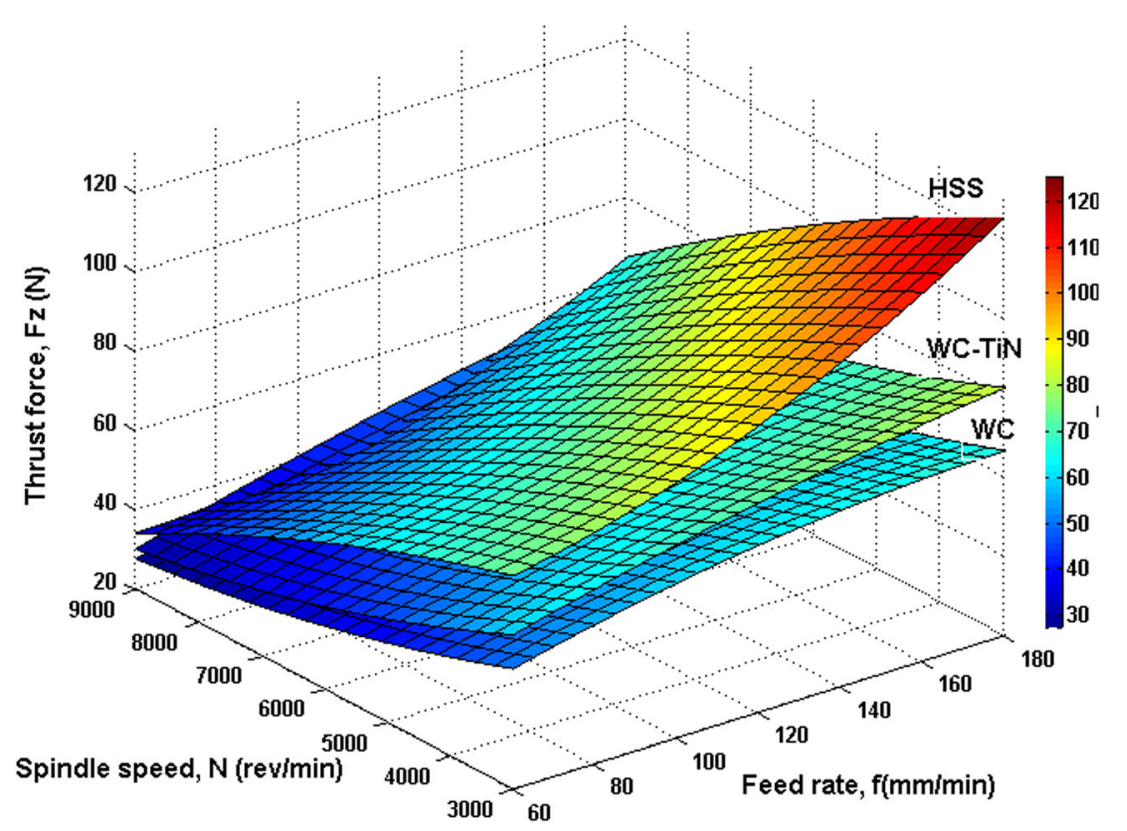


Fig. 5 Effect of spindle speed and feed rate on torque for HSS, carbide, and TiN-coated carbide

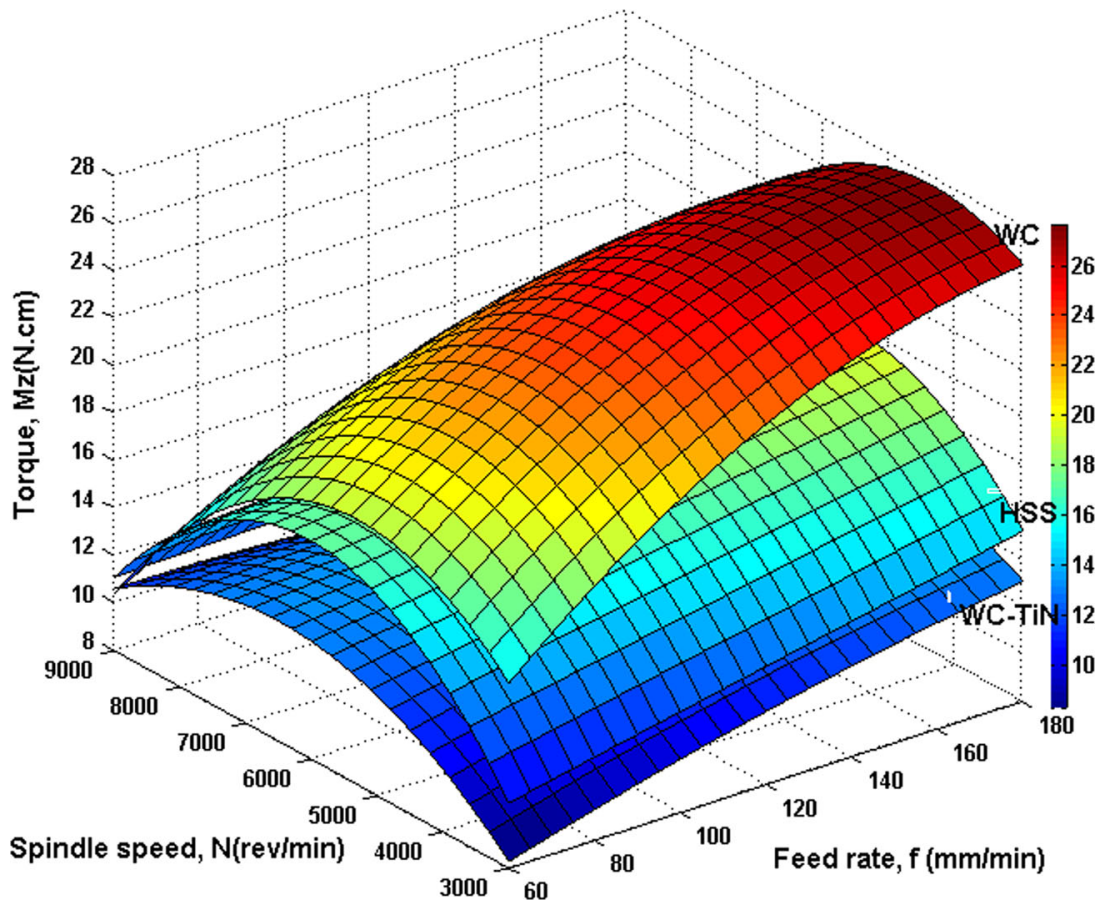

exit of the holes, and that delamination decreases with a high cutting speed (9000 rev/min).

Again according to Fig. 6, it is observed that the rise in spindle speed slightly diminishes the exit delamination factor. The reason for this is that the temperature produced in the drilling of composites increases with the spindle speed, which softens the matrix material and increases shearing, which diminishes delamination. The high feed rate increases both the thrust force in drilling and the exit delamination factor [11].
This result can be explained by the fact that at high cutting speed, the cutting edge action is reduced, and that the friction between cutting edges and board causes temperature elevation and softening, thus reducing damage.

\subsection{Effect of machining parameters on cylindricity error}

The influence of the feed rate and spindle speed on the cylindricity error using the HSS, WC, and WC-TiN drills is illustrated in Fig. 7. It can be observed that the cylindricity

Fig. 6 Effect of spindle speed and feed rate on exite delamination factor $\left(F_{d \text {-exit }}\right)$ for HSS, carbide, and TiN-coated carbide

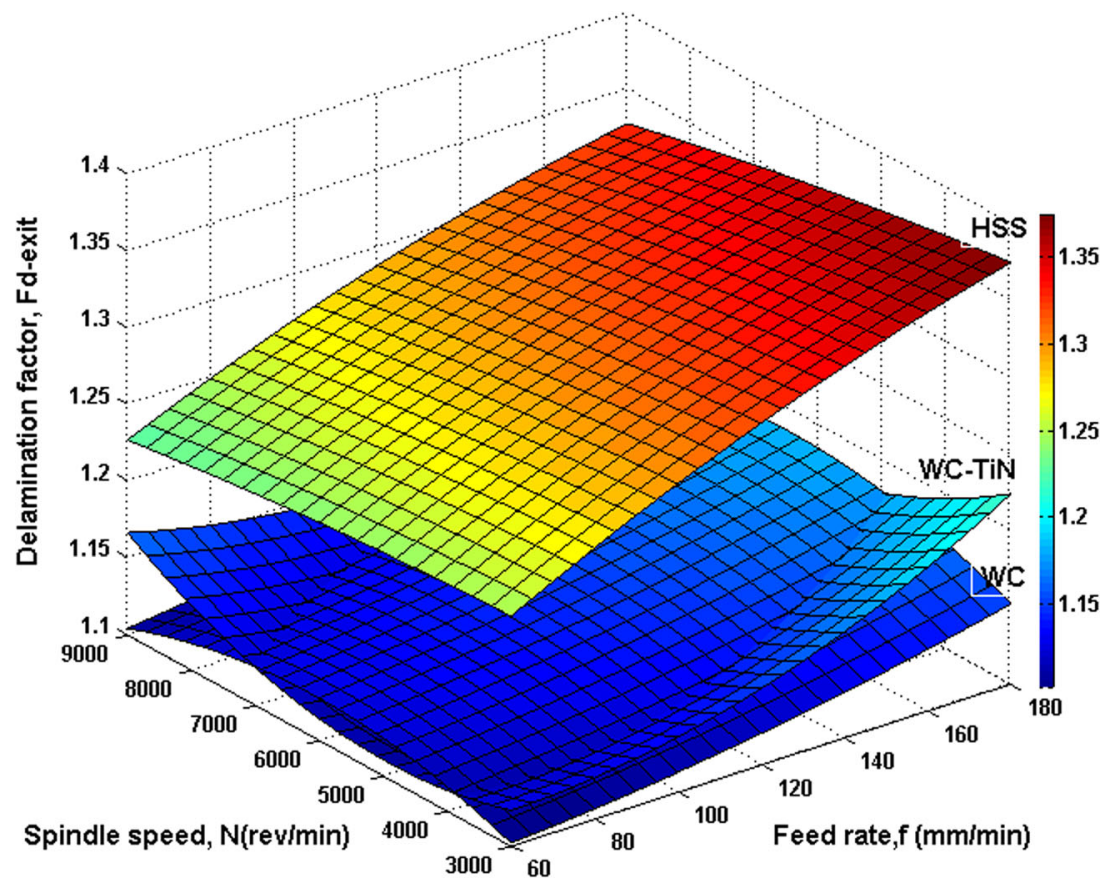


Fig. 7 Effect of spindle speed and feed rate on cylindricity error for HSS, carbide, and TiN-coated carbide

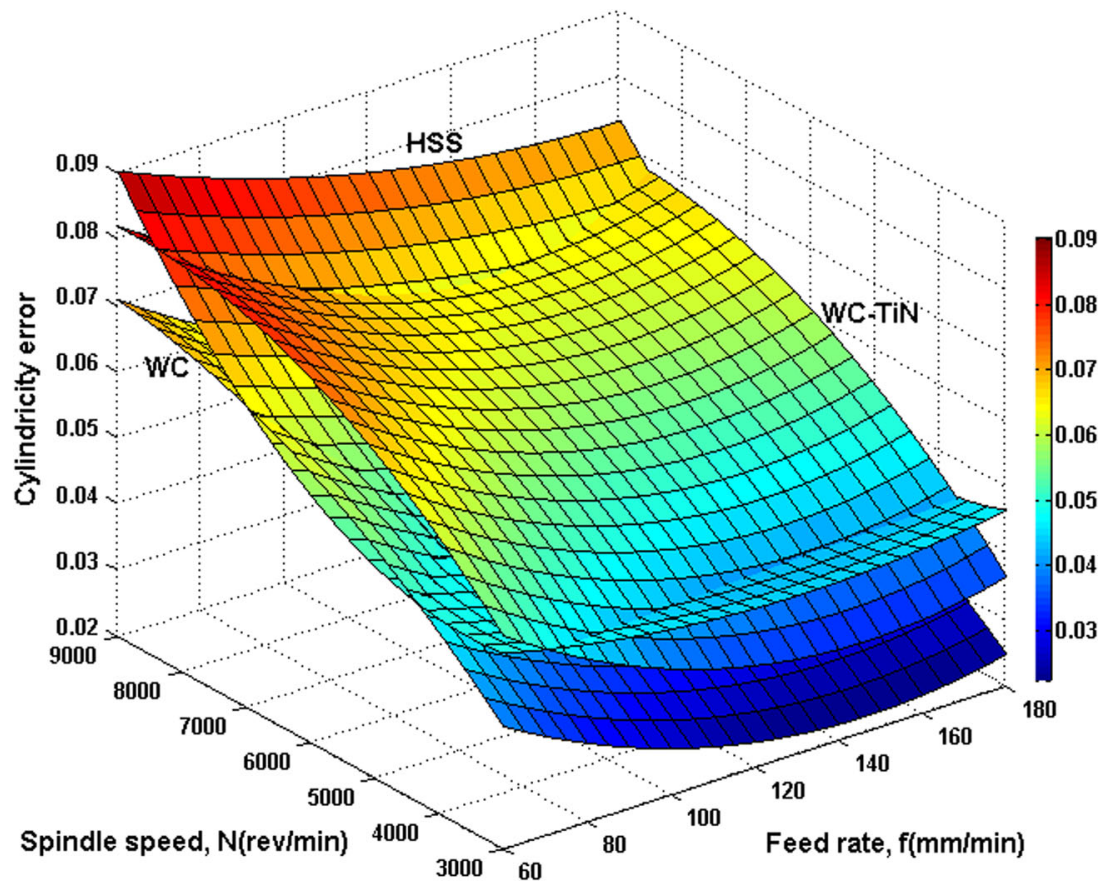

Observations, as illustrated in Fig. 8, show that the surface

error is related linearly to both spindle speed and feed rate. The high spindle speed increases the cylindricity error in the drilling of composite materials for the different drills (HSS, $\mathrm{WC}$, and WC-TiN). It is the most influential parameter on the quality of the holes, in particular the cylindricity error. On the other hand, the effect of the feed rate on the cylindricity error is insignificant for the lowest spindle speed, $3000 \mathrm{rev} / \mathrm{min}$, and only slight for the highest spindle speed of $9000 \mathrm{rev} / \mathrm{min}$.

It was concluded that the combination between the maximum spindle speed and the minimum feed rate for the three tools gives a maximum cylindricity error. Hence, the smallest cylindricity error is obtained from the combination of the lowest spindle speed and the highest feed rate.

\section{Surface quality of machined holes}

SEM observation revealed several damaged areas when the holes were machined with a WC twist drill, as shown in Fig. 8. These damaged areas were mainly observed at fiber orientations of $-45^{\circ}$ and $90^{\circ}$. However, in WC-Ti machining, there were fewer damage areas and lower depths of damage compared to WC drilling. Also, it was found that damage was uniformly distributed. Figure 8 displays the SEM observation of the last nine cut composite layers $\left(90^{\circ}, 45^{\circ}, 0^{\circ},-45^{\circ}, 90^{\circ}\right.$, $45^{\circ}, 0^{\circ}$, and $-45^{\circ}$ ) for the holes drilled into the CFRE composite.

The SEM photograph illustrates several cases of fiber pullout and a series of interlaminar delamination damage. The extent of this damage depends mainly on the fiber orientation and the cutting parameters [22]. hole accumulated melted matrix material between the plies. This is possibly caused by the increased tool-workpiece contact time coupled with a low feed rate leading to relatively higher interfacial temperatures. The weak thermal conductivity of CFRE was a further contributory factor in causing the resin to melt.

A close-up view of the distribution of fibers at a $90^{\circ}$ angle is illustrated in Fig. 8a. The material removal is initiated by an opening, which penetrates the material below the cutting direction, according to the fiber/matrix interface, extended by a secondary rupture, which rises to the shear fibers, as shown in Fig. 9a [23].

The SEM analysis also illustrates that the cutting of the fibers of plies with $-45^{\circ}$ orientation causes pullout of the

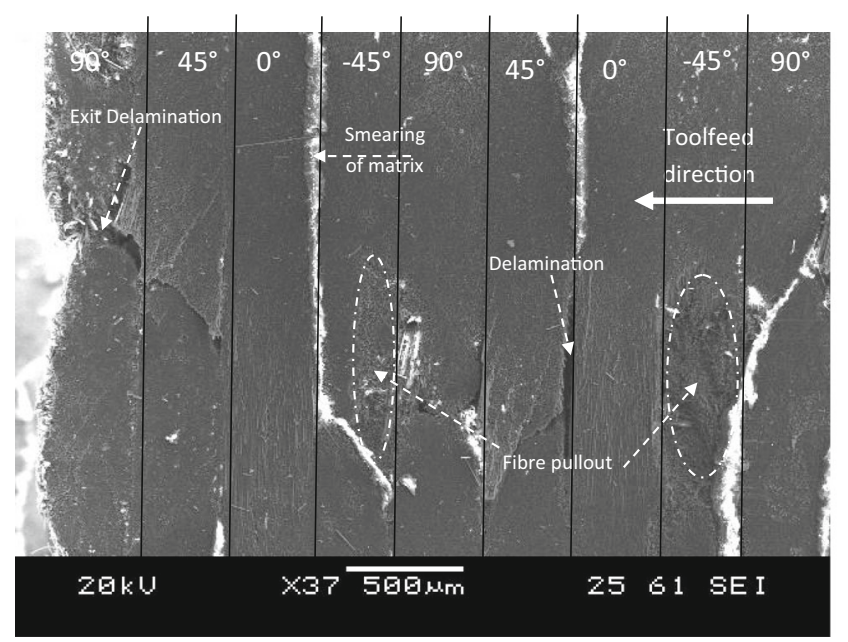

Fig. 8 SEM photographs of the damages observed of hole drilled 
fibers, leading to significant damage in the form of cavities (see Fig. 8). With the cutting of $-45^{\circ}$ oriented fibers illustrated in Fig. 9b, the fibers bend. Significant defects propagate inside the material and eventually pullout and tear the fibers [24, 25].

Chip separation occurs after fiber rupture in a direction perpendicular to their axis. During the cutting of plies at $0^{\circ}$ orientation, the tool delaminates the fibers easily creating small defects Fig. 8. Machining of fibers at $0^{\circ}$ can produce large fragmented debris. The fibers are stressed and this induces buckling which causes cracking (Fig. 9c).

For plies of $45^{\circ}$ orientation, the chip formation mechanisms begin with shearing of the fibers and then of the matrix, along the fiber/matrix interface to the free surface, as illustrated in Fig. 9c. During cutting of the fibers oriented at $45^{\circ}$, the cutting tool reached the layer directly, and very small composite debris were formed.

It can be seen that the drilling of composites produces tiny fiber particle chips, as shown in Fig. 10, with dimensions not exceeding roughly $20 \mu \mathrm{m}$.

\section{Confirmation experiments}

The comparison between the expected values of the model developed in the present work (Eqs. 1 to 15 ) and the values obtained experimentally is shown in Table 5. It illustrates the calculated errors as follows: thrust force $(F z)$ (max. value $3.41 \%$ and min. value $0.64 \%$ ), torque $(M z)$ (max. value $4.36 \%$ and min. value $2.80 \%)$, exit delamination factor $\left(F_{d-}\right.$
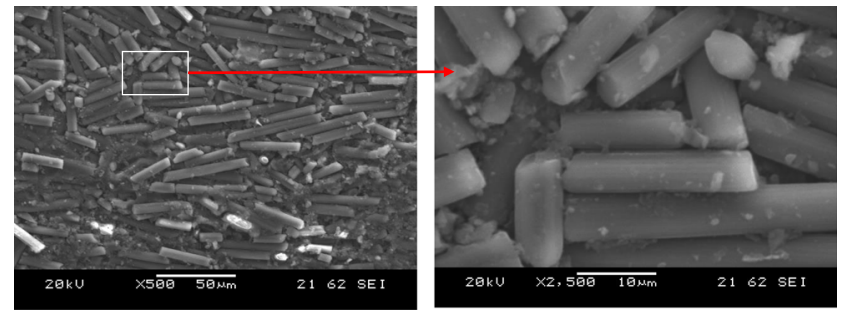

Fig. 10 SEM photographs of the CFRE chips

Exit) (max. value $3.20 \%$ and min. value $0.76 \%$ ), and cylindricity error $(\mathrm{mm})$ ( $\max$. value $2.82 \%$ and $\mathrm{min}$. value $1.45 \%$ ). All the confirmation experiment values are within the $95 \%$ prediction interval. Therefore, Eqs. (1) to (15) correlated the evolution of thrust force, torque, exit delamination factor, and cylindricity error with the cutting conditions (spindle speed and feed rate) with a reasonable degree of approximation.

\section{Optimization of cutting conditions}

In this study, a desirability function approach was used for multiple response parameters, namely thrust force $(\mathrm{Fz})$, torque $(M z)$, exit delamination factor $\left(F_{d \text {-Exit }}\right)$, and cylindricity error. Design-Expert software was used for this optimization exercise. During the optimization process, the aim was to find the optimal values of machining parameters in order to produce the lowest thrust force, torque, surface roughness, and cutting
Fig. 9 SEM photographs of fracture of the hole drilled at different orientations of fiber. a $90^{\circ}$ orientated plies, $\mathbf{b}-45^{\circ}$ orientated plies, $\mathbf{c} 0^{\circ}$ orientated plies, and $\mathbf{d} 45^{\circ}$ orientated plies

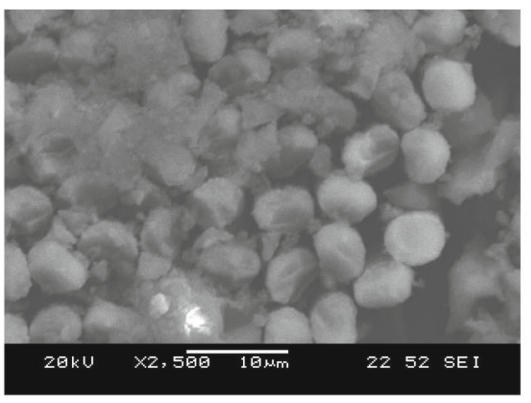

a) $90^{\circ}$ orientated plies

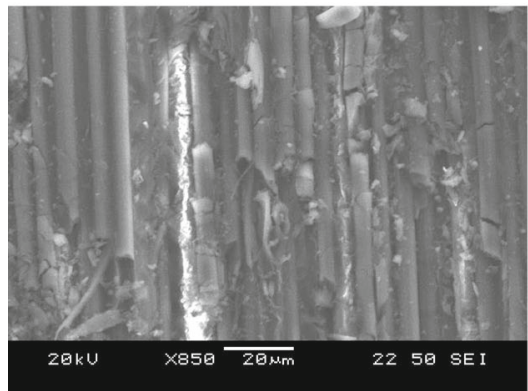

c) $0^{\circ}$ orientated plies

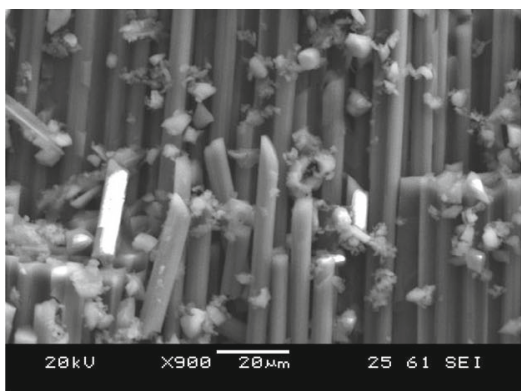

b) $-45^{\circ}$ orientated plies

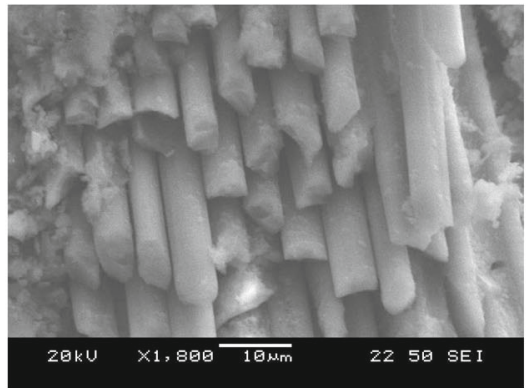

d) $45^{\circ}$ orientated plies 
Table 5 Confirmation of experiment results

\begin{tabular}{|c|c|c|c|c|c|c|}
\hline \multirow[t]{2}{*}{ Exp. $N^{\circ}$} & \multicolumn{3}{|c|}{ Design parameters } & \multicolumn{3}{|c|}{ For regression equations } \\
\hline & $N(\mathrm{rev} / \mathrm{min})$ & $f(\mathrm{~mm} / \mathrm{min})$ & Tools & Exp. & Predict. & Error \% \\
\hline \multicolumn{7}{|c|}{ Thrust force $(F z)$} \\
\hline 1 & 3000 & 180 & HSS & 114.32 & 115.06 & 0.64 \\
\hline 2 & 3000 & 180 & WC & 73.91 & 76.52 & 3.41 \\
\hline 3 & 3000 & 180 & WC-TiN & 65.08 & 67.27 & 3.25 \\
\hline \multicolumn{7}{|c|}{ Torque $(M z)$} \\
\hline 1 & 3000 & 180 & HSS & 17.11 & 17.83 & 4.04 \\
\hline 2 & 3000 & 180 & WC & 10.30 & 10.77 & 4.36 \\
\hline 3 & 3000 & 180 & WC-TiN & 11.02 & 10.72 & 2.80 \\
\hline \multicolumn{7}{|c|}{ Exit delamination factor } \\
\hline 1 & 6000 & 180 & HSS & 1.29 & 1.25 & 3.20 \\
\hline 2 & 6000 & 180 & WC & 1.30 & 1.31 & 0.76 \\
\hline 3 & 6000 & 180 & WC-TiN & 1.17 & 1.18 & 0.85 \\
\hline \multicolumn{7}{|c|}{ Cylindricity error (mm) } \\
\hline 1 & 9000 & 60 & HSS & 0.073 & 0.071 & 2.82 \\
\hline 2 & 9000 & 60 & WC & 0.042 & 0.041 & 2.44 \\
\hline 3 & 9000 & 60 & WC-TiN & 0.068 & 0.069 & 1.45 \\
\hline
\end{tabular}

temperature. To solve this type of parameter design problem, an objective function, $F(x)$, is defined as follows [21]:

$$
\begin{aligned}
& D F=\left(\prod_{i=1}^{n} d_{i}^{w}\right) \overline{\sum_{j-1}^{n} w_{i}} \\
& F(x)=-D F
\end{aligned}
$$

with $d_{i}$ the desirability defined for the $i$ th required output and $w_{i}$ the weighting of $d_{i}$.

For different objectives of required output, the desirability $d_{i}$ is defined in variable forms. If an objective is to attain a particular value of $T i$, the desirability $d_{i}$ becomes:

$$
\begin{array}{rlcc}
d i & =0 \text { if } Y_{i} \leq \mathrm{Low}_{i} & \text { or } & Y_{i} \geq \operatorname{High}_{i} \\
d_{i}=\left[\frac{Y_{i}-\mathrm{Low}_{i}{ }^{i}}{T_{i}-\mathrm{Low}_{i}}\right] & \text { if } & \mathrm{Low}_{i} \leq Y_{i} \leq T_{i} \\
d_{i}=\left[\frac{Y_{i}-\mathrm{High}_{i}^{i}}{T_{i}-\mathrm{High}_{i}}\right] & \text { if } & T_{i} \leq Y_{i} \leq \operatorname{High}_{i}
\end{array}
$$

where $Y i$ is the value found of the $i$ th output during the optimization process and $\mathrm{Low}_{i}$ and $\mathrm{High}_{i}$ are the minimum and maximum values for the same output. If the objective is to find the maximum value, the desirability will be:

$$
\begin{aligned}
d i & =0 \quad \text { if } \quad Y_{i} \leq \operatorname{Low}_{i} \quad \text { or } \quad Y_{i} \geq \operatorname{High}_{i} \\
d_{i} & =\left[\frac{Y_{i}-\operatorname{Low}_{i}{ }^{i}}{\operatorname{High}_{i}-\operatorname{Low}_{i}}\right] \quad \text { if } \quad \operatorname{Low}_{i} \leq Y_{i} \leq \operatorname{High}_{i}
\end{aligned}
$$

If the objective is to find a minimum value, the desirability is defined as follows:

$$
\begin{aligned}
d_{i} & =0 \quad \text { if } \quad Y_{i} \leq \operatorname{Low}_{i} \quad \text { or } \quad Y_{i} \geq \operatorname{High}_{i} \\
d_{i} & =\left[\frac{\operatorname{High}_{i}-Y_{i}^{i}}{\operatorname{High}_{i}-\operatorname{Low}_{i}}\right] \quad \text { if } \quad \operatorname{Low}_{i} \leq Y_{i} \leq \operatorname{High}_{i}
\end{aligned}
$$

In Eq. (16), $w_{i}$ is put as equal to one, since the $d_{i}$ all have the same weight in this work. $D F$ is a combined desirability
Table 6 Constraints for optimization of cutting conditions

\begin{tabular}{lllll}
\hline Condition & Goal & Lower limit & Upper limit & Importance \\
\hline Spindle speed, $N(\mathrm{rev} / \mathrm{min})$ & Is in range & 3000 & 9000 & \\
Feed rate, $f(\mathrm{~mm} / \mathrm{min})$ & Is in range & 60 & 180 & \\
Tool materials & Is in range & $(1) \mathrm{HSS},(2) \mathrm{WC},(3)$ WC-TiN & $*$ * \\
Thrust force $(F z)$ & Minimize & 28.34 & 121.6 & $* * * *$ \\
Torque $(M z)$ & Minimize & 8.23 & 27.45 & $* * * * *$ \\
Exit delamination $\left(F_{d \text {-Exit }}\right)$ & Minimize & 1.081 & 1.368 & $* * * * *$ \\
Cylindricity error & Minimize & 0.025 & 0.091 & \\
\hline
\end{tabular}


Table 7 Optimization results

\begin{tabular}{lllllllll}
\hline Solution $\mathrm{N}^{\circ}$ & $N(\mathrm{rev} / \mathrm{min})$ & $f(\mathrm{~mm} / \mathrm{min})$ & Tool materials & $F z(\mathrm{~N})$ & $M z(N . \mathrm{cm})$ & $F_{d \text {-Exit }}$ & Cylindricity (mm) & Desirability \\
\hline 1 & 3000 & 68.87 & WC-TiN & 58.28 & 8.85 & 1.125 & 0.03756 & 0.851 \\
2 & 3000 & 68.19 & WC-TiN & 58.16 & 8.80 & 1.125 & 0.03778 & 0.851 \\
3 & 3000 & 67.12 & WC-TiN & 57.98 & 8.72 & 1.125 & 0.03813 & 0.851 \\
4 & 3000 & 71.67 & WC-TiN & 58.76 & 9.06 & 1.126 & 0.03669 & 0.851 \\
5 & 3000 & 70.93 & WC-TiN & 58.59 & 9.03 & 1.126 & 0.03695 & 0.850 \\
6 & 3000 & 69.78 & WC-TiN & 58.41 & 8.94 & 1.126 & 0.03731 & 0.850 \\
7 & 3000 & 62.38 & WC-TiN & 57.17 & 8.35 & 1.123 & 0.03972 & 0.850 \\
8 & 3000 & 61.45 & WC-TiN & 57.01 & 8.28 & 1.123 & 0.04004 & 0.850 \\
\hline
\end{tabular}

function. The purpose here is to find the best solution that maximizes a combined desirability function $D F$, i.e., minimizes $F(x)$.

The optimal manufacturing conditions for the drilling of composite CFRE with the constraints of the cutting parametric range are those corresponding to the lowest values of thrust force $(F z)$, torque $(M z)$, exit delamination factor $\left(F_{d \text {-Exit }}\right)$, and cylindricity error during the dry drilling process. The constraints used during the optimization process are summarized in Table 6, whereas the optimal solutions are reported in Table 7. This same table shows the RSM optimization results for thrust force, torque, exit delamination factor, and cylindricity error. The optimum cutting parameters in Table 7 were obtained with a spindle speed of $3000 \mathrm{rev} / \mathrm{min}$, a feed rate of (61.45 to 71.67$) \mathrm{mm} / \mathrm{min}$, and the WC-TiN tool material. The optimized thrust force, torque, $F_{d \text {-Exit }}$, and cylindricity error are (57.01 to 58.76$) \mathrm{N}$, (8.28 to 9.06$) \mathrm{N} \times$ $\mathrm{cm},(1.040$ to 1.041$),(1.123$ to 1.126$)$, and $(0.03669$ to $0.04004) \mathrm{mm}$, respectively.

\section{Conclusions}

This research work presents the application of RSM models to the study of the influence of machining parameters on thrust force, torque, exit delamination factor, and cylindricity error.

The relationship between the factors and the measured performance were modeled by quadratic regression. Three process variables, namely spindle speed, feed rate, and tool materials, were used for the development of the models. The RSM models were developed then tested using ANOVA. The actual models were found to satisfy the optimization of the machining parameters at a $95 \%$ confidence interval. Through this analysis, conclusions about machining force, exit delamination factor, and cylindricity error were deduced:

- Drilling forces were significantly influenced by tool materials. Since the degree of drilling force induced in the drilling process is associated with the power requirements, which is in turn correlated to production costs, a low thrust force and torque were preferred. In this study, coated carbide (WC-Ti) drills induced the lowest drilling forces while HSS drills produced the highest drilling forces. Therefore, coated carbide drills present more advantages for CFRE composites drilling.

- The 3D response surface plots clearly indicate the existence of non-linear relationships between the process parameters and the machinability characteristics and thus justifying the use of a quadratic model.

- The error associated with the ANOVA table (maximum value $4.36 \%$ and minimum value $0.64 \%$ ) for the factors and the coefficients was obtained by the quadratic regression (maximum value $92.33 \%$ and minimum value $83.48 \%$ ).

- Comparison of experimental and predicted values of thrust force, torque, exit delamination factor, and cylindricity error shows that the good agreement has been achieved between them. Therefore, the developed model can be recommended for use in predicting thrust force, torque, exit delamination factor, and cylindricity error.

- Verification of the experiments carried out shows that the empirical models developed can be used for CRFE composites drilling.

- Hence, it is clear that a reduction in the cylindricity error for drilling composites can be achieved by using a low spindle speed and high feed rate.

- The recommended levels of the drilling parameters allowing minimal thrust force, torque, exit delamination factor, and cylindricity error simultaneously are the feed rate at level $1(\sim 60 \mathrm{~mm} / \mathrm{min})$, the drill type at level 3 (WCTi), and the spindle speed at level 1 (3000 rev/min).

$F z$, thrust force $(N)$; HSS, high-speed steel; $M z$, torque $(N \times$ $\mathrm{cm}) ; N$, spindle speed (rev/min); $f$ feed rate $(\mathrm{mm} / \mathrm{s}) ; F_{d \text {-Exit }}$, factor of delamination-exit.

Acknowledgments This work was completed in the Laboratory of Materials Science and Engineering (University USTHB, Algeria) in collaboration with the Laboratory of Innovative Technologies (LTI), University of Picardie Jules Verne, France). The authors would like to thank the Algerian Ministry of Higher Education and Scientific Research (MESRS) and the Delegated Ministry for Scientific Research (MDRS) for granting financial support for CNEPRU. 


\section{References}

1. Chen WC (1997) Some experimental investigations in the drilling of carbon fibre reinforced composite laminations. Int J Mach Tools Manuf 37(8):1097-1108

2. Paulo Davim J, Reis P (2003) Drilling carbon fiber reinforced plastics manufactured by autoclave experimental and statistical study. Mater Des 24:315-324

3. Davim JP, Reis P (2003) Study of delamination in drilling carbon fiber reinforced plastic (CFRP) using design experiments. Compos Struct 59:481-487

4. Tsao CC (2008) Experimental study of drilling composite materials with step-core drill. Mater Des 29:1740-1744

5. Zitoune R, El M, Krishnaraj V (2013) Tribo-functional design of double cone drill implications in tool wear during drilling of copper mesh/CFRP/woven ply. Wear 302:1560-1567

6. Lia MJ, Sooa SL, Aspinwalla DK, Pearsonb D, Leahyc W (2014) Influence of lay-up configuration and feed rate on surface integrity when drilling carbon fibre reinforced plastic (CFRP) composites. Procedia CIRP 13:399-404

7. Gaitonde VN, Karnik SR, Rubio Campos J, Correia Esteves A, Abrao AM, Paulo Davim J (2008) Analysis of parametric influence on delamination in high-speed drilling of carbon fiber reinforced plastic composites. J Mater Process Technol 203:431-438

8. Rawat S, Attia H (2009) Characterization of the dry high speed drilling process of woven composites using machinability maps approach. CIRP Annals ManufTechnol 58:105-108

9. Piquet R, Ferret B, Lachaud F, Swider P (2000) Experimental analysis of drilling damage in thin carbon/epoxy plate using special drills. Compos Part A 31:1107-1115

10. Durão LMP, Tavares JMRS, de Albuquerque VHC, Gonçalves DJS (2013) Damage evaluation of drilled carbon/epoxy laminates based on area assessment methods. Compos Struct 96:576-583

11. Capello E (2004) Workpiece damping and its effect on delamination damage in drilling thin composite laminates. J Mater Process Technol 148:186-195

12. Bhatnagar N, Ramakrishnan N, Naik NK, Komanduri R (1995) On the machining of fiber reinforced plastic (FRP) composite laminates. Int J Mach Tools Manuf 35:701-716

13. Rajamurugan TV, Shanmugam K, Palanikumar K (2013) Analysis of delamination in drilling glass fiber reinforced polyester composites. Mater Des 45:80-87
14. Khashaba UA, EI-Sobaty IA, Selmy AI, Megahed AA (2010) Machinability analysis in drilling woven GFR/epoxy composites: part I-effect of machining parameters. Compos Part A 41: 391-400

15. Rubio Juan Carlos C, Rubio JCC, da Silva LJ, de Oliveira Leite Tulio Hallak Panzera W, Sergio Luiz Moni Ribeiro F, João Paulo D (2013) Investigations on the drilling process of unreinforced and reinforced polyamides using Taguchi method Composites. Part B Eng 55:338-344

16. Sardinas RQ, Reis P, Davim JP (2006) Multi-objective optimization of cutting parameters for drilling laminate composite materials by using genetic algorithms. Compos Sci Technol 66:3083-3088

17. Krishnamoorthy A, Rajendra Boopathy S, Palanikumar K, Paulo Davim J (2012) Application of grey fuzzy logic for the optimization of drilling parameters for CFRP composites with multiple performance characteristics. Measurement 45:1286-1296

18. DeFuLiu YJT, Cong WL (2012) A review of mechanical drilling for composite laminates. Compos Struct 94:1265-1279

19. Aouici H, Bouchelaghem H, Yallese MA, Elbah M, Fnides B (2014) Machinability investigation in hard turning of AISI D3 cold work steel with ceramic tool using response surface methodology. Int J Adv Manuf Technol 73:1775-1788

20. Haijin W, Jie S, Jianfeng L, Laixiao L, Nan L (2016) Evaluation of cutting force and cutting temperature in milling carbon fiberreinforced polymer composites. Int J Adv Manuf Technol 82(9): 1517-1525

21. Shahrajabian H, Farahnakian M (2013) Modeling and multiconstrained optimization in drilling process of carbon fiber reinforced epoxy composite. Int J Precis Eng Manuf 14:1829-1837

22. Rubio JCC, Abrao AM, Faria PE (2008) Delamination in high speed drilling of carbon fiber reinforced plastic (CFRP). J Compos Mater 42(15):1523-1532

23. Sahraie Jahromi A, Bahr B, Krishnan KK (2014) An analytical method for predicting damage zone in orthogonal machining of unidirectional composites. J Compos Mater 48(27):3355-3365

24. Zhenchao Q, Kaifu Z, Hui C, Dong W, Qingxun M (2015) Microscopic mechanism based force prediction in orthogonal cutting of unidirectional CFRP. Int J Adv Manuf Technol 79:1209-1219

25. Cadorin N, Zitoune R, Seitier P, Collombet F (2015) Analysis of damage mechanism and tool wear while drilling of 3D woven composite materials using internal and external cutting fluid. J Compos Mater 49(22):2687-2703 